九州大学学術情報リポジトリ

Kyushu University Institutional Repository

\title{
Key Issues in the Process of Rural Economy Development in Vietnam
}

Dinh, Pham Van

Assoc.Prof., Vice Dean, Faculty of Economics and Rural Development, Hanoi Agricultural University

Murata, Takeshi

Laboratory of Agricultural Policy, Division of International Agricultural Resouce Economics and Business Administration, Department of Agricultural and Resouce Economics, Faculty of Agriculture, Kyushu University

Hung, Pham Van

Lecturer, Faculty of Economics and Rural Development, Hanoi Agricultural University

https://doi.org/10.5109/24414

出版情報: 九州大学大学院農学研究院紀要. 45 (2)，pp.643-650，2001-02-28. Kyushu University バージョン：

権利関係 : 


\title{
Key Issues in the Process of Rural Economy Development in Vietnam
}

\author{
Pham Van Dinh*, Takeshi Murata**, and Pham Van Hung*** \\ Laboratory of Agricultural Policy, Division of International Agricultural Resource Economics \\ and Business Administration, Department of Agricultural and Resource Economics, \\ Faculty of Agriculture, Kyushu University, Fukuoka, 812-8581, Japan. \\ (Received October 31, 2000 and accepted November 10, 2000)
}

\begin{abstract}
The Vietnamese rural economy has undergone vast changes in the last two decades, particularly since the implementation of the Resolution No. 10 (1988) and Law on Land (1993). As a result, poverty has fallen from $25 \%$ in 1993 to $15 \%$ in 1998 and $11 \%$ in 2000 (MOLISA, 2000 ). The agricultural GDP has been growing at an annual average of 4.1 per cent annually between 1990 and 1999 . The biggest change is observed in food production which has led Vietnam from being an importer of rice to being the world's second largest rice exporter behind Thailand. However, Vietnam is still facing many challenges. In rural areas, unemployment and underemployment are still very high, poverty and malnutrition are rural phenomenon. Agricultural growth has declined over the last few years. The agricultural products prices are relative low and farmers now face the prospect of stagnant incomes. Besides that, rural infrastructure, technology and management are still very poor. Given these challenges, several key issues are closely interrelated and will need to be addressed simultaneously. The present report suggested the key issues for rural development in Vietnam would be (1) redistribution of rural and agricultural labors; (2) efficient use of agricultural land; (3) shifting rural economic structure; (4) development of cooperatives under the Cooperative Law; (5) rural economy investment; (6) reform agricultural price policy; and (7) participation of poor rural people in the market oriented rural economy. The analysis and understanding of each issue are needed for further development of this sector in Vietnam.
\end{abstract}

\section{INTRODUCTION}

In contrast to the other Southeast Asian countries, Vietnam remains a predominantly agrarian society. 76.5 percent of the total population live in rural areas and almost two-thirds of them depend on farming for a living (Results of Population Census, 1999). Since the introduction of DOI MOI (renovation) policy in 1986, and particularly during the last decade, rural areas in Vietnam have experienced dramatic changes. While overall agricultural output and productivity have risen significantly, the achievements in the rice sector have been spectacular, transforming Vietnam from a net importer of rice into the world's second largest exporter. In 1999, the production of rice reached 31 million tons and rice exports were up to 4.5 million tons. As a results, food security has been achieved

* Assoc. Prof., Vice Dean, Faculty of Economics and Rural Development, Hanoi Agricultural University, Vietnam (JICA participant in Kyushu University, Jul. 30-Sep. 10, 2000)

** Professor, Faculty of Agriculture, Kyushu University

*** Lecturer, Faculty of Economics and Rural Development, Hanoi Agricultural University, Vietnam (JICA participant in Kyushu University, Jul. 30, 2000-Jan. 28, 2001) 
at the aggregate level. The income of rural people and overall well-being in rural areas have improved. Such as more people have accessed to clean water, better sanitation and improved health care. In addition, production resources have mobilized widely and used efficiently; a number of new production models and economic relationships have been established and developed in rural areas. This resulted an improvement of agricultural intensification; wide application of advanced technologies; revitalization and development of handicraft and service sectors; maintenance and improvement of the infrastructure; etc. These changes have resulted great achievements such as diversification of agriculture and rural economy, and positive changes in rural economy structure. The living standards of rural people are also improved. For instance, the average expenditure per rural household was VND 7,881.46 thousand (Vietnam Dong), while this number for whole country was VND 9,116.71 thousand; proportions of rural households having good houses, color televisions, and motorcycles, were in turn $64.07 \%, 11.22 \%$, and $11.61 \%$, respectively. The number of households having refrigerators, and telephones were few $(0.93 \%$ and $0.29 \%$, respectively). About 53.7 and $31.17 \%$ of total farmer households were used electricity and accessed safety water, respectively (Vietnam Living Standards Survey, 1997-98).

In spite of these changes, rural economy in Vietnam is still lying the stagnated and weak conditions and it has not met an increasing demand. Vietnam has too many farmers and too few sources of off-farm income (UN, 1998a). More than one million people, most of them are in rural areas, are entering the labor force annually. At the same time, some 6-7 million rural working-age people are believed to lack permanent work, and rural underemployment is estimated at up to $35 \%$ (UNDP, 1998a). The income per capita of rural people is still too low. Poverty is mostly a rural phenomenon, and 90 percent of all the poor live in rural areas (UNDP, 2000). In 1998, the average for whole country was 15 percent of the population living under poverty line'. Furthermore, 1,715 communes (nearly 20 per cent of the total) have been classified as poor; two-third of them are located in mountainous areas. In addition, other demands for living; travel; education; health care, etc. are meeting at very low levels. The Vietnamese agriculture is still characterized by small, scattered, and self-sufficient production: besides that it was also characteristically low productivity and poor post-harvest processing technologies, especially in remote and bad natural conditions areas (the Northern Uplands, Central Highlands, and the North Central Coast). Therefore, there are many challenges to be considered in the process of economic development.

In order to overcome the above mentioned problems, various policies has been promulgated in the recent years. The land policy has brought the powerful effects on rural economy and the whole economy as well; and social equality. The agricultural extension policy has considerably contributed to farmer's knowledge improvement of

\footnotetext{
'In Vietnam, several methodologies have been used to date to measure poverty (introduced by the Ministry of Labor, Invalid and Social Affair (MOLISA); General Statistical Office (GSO); and World Bank (WB). Based on MOLISA method (a narrow definition of "poverty" or "food poverty"), the poverty level has declined from $24.9 \%$ in 1993 to $15 \%$ in 1998 and $11 \%$ in 2000 . However, a new criteria for poverty was set up by MOLISA and it will be in effective in 2001. When a wider definition of poverty was applied (such as method of World Bank), the poverty level has dropped from $58 \%$ in 1993 to $37 \%$ in 1998.
} 
agricultural production, especially use of new variety, integrated pest management (IPM), and new technology. The credit policy had also big contribution in capital demand of farmers. The policy of multi-sector economic development has resulted in dynamic economic development in rural areas. New Cooperative Law has generated new perception of farmers on cooperatives, new production organization, and active support to household economy.

The new situation has created not only new opportunities for economic development but also new challenges for it. The opportunities are natural conditions, especially advantages of land and climate conditions allowing to develop diversified agriculture; rapid technological change in the world and nation wide; the integration into the regional and world economy. In order to use these opportunities, big questions to be answered are: (a) how to efficiently use available resources in rural areas, (b) how to joint in the world and regional economy, and (c) how to develop a sustainable agriculture?

The weaknesses of old management mechanism have generated the economic stagnation. After Resolution No. 10 (April, 1988) of Politburo and New Land Law (1993) and Ordinance $64 / \mathrm{cp}$ that allocated agricultural land to the farmers for long term use promulgated, what policy should be needed to improve living standards of rural people? The new management mechanism has created new economic production force for remove the barriers of the economy only but not rapid growth and sustainable development of rural economy, yet. The development of household economy in the last years has solved a food problem. However, due to rapid population growth and main income of rural people coming from agriculture, the intensification, crop rotations, and agricultural extension are not enough for well-being of rural people. This means that beside farming income, rural people should find out other sources outside farm activities.

In the last few years, there were two types (groups) of farm households increased their incomes were observed in rurl areas as following:

- A group of households has increased working days of the family labors through increasing intensive crops, agricultural intensification, production diversification, handicraft and service development, and working as hired laborers. The household income will be raised when increasing working days. However, due to mainly manual labors, average income per working day is still very low. These households can be classified as the relatively above average in rural areas.

- Other group of households has developed to family farms through land consolidation or establish off-farm activities (handicraft and services). However, this group of households occupies very small in number.

Besides these two types of households, remain farmers are still facing with difficulties in production and earning income. New jobs and high income jobs are therefore emerged problems to be paid more attention at present. If agricultural labor force is moved to other sectors, so working days of remained labors in agriculture will be raised and consequently household income will be improved. However, this is not easy because labors and population are concentrated mainly in rural areas. In addition, inefficient use of resources, environment, and infrastructure degraded are main reasons for low economic efficiency. 


\section{KEY ISSUES FOR RURAL DEVELOPMEN'T}

For rural development under this status, some followings are should be considered:

\section{Redistribution of Rural and Agricultural Labors}

At present, due to labor surplus at around $35 \%$ in rural areas, generating employment opportunity is very essential. The solutions should be:

- To move labor forces from agriculture to other sectors based on demand for industrial and off-farm labors. In order to move to industry, agricultural labors need to be trained according to the requirements of its technology. Training courses for these laborers should be conducted. Besides, forecasting labor demand of industrial sector is necessary for organization appropriate training courses.

- To continue the fallow land use policy to adjust population density among regions in the whole country.

- Within rural areas, the followings should be done for redistribution of labor force:

(a) To improve competitiveness of handicraft products;

(b) To introduce and increase consumption of processed products;

(c) To apply new technology for increasing demand for production inputs and purchasing power of farmers; and

(d) To improve farmers perception and their activeness.

Thus, in the process of redistribution of labor force, a policy should encourage establish small and medium enterprises in rural areas, enlarge markets via diversifying production and applying new production technology.

\section{Efficient Agricultural Land Use}

At present, agricultural land is very scattered and dispersed. In the whole country, there are over 72 million land plots for around 10 million farm households, in an average of 7 plots/household (some cases from 15 to 20 plots) (Nguyen Huu Tien, 1999). Following Land Law in most areas, farmers are exchanging agricultural land to each other. It is necessary to summary experiences of this process to speed up land consolidation process in rural areas and issuing more appropriate policies.

Land consolidation will result in favorable environments for investment, application of new technology, and increase land fertility. In market economy, however, the objective of the land use is not only the high yields, but also the high economic efficiency. Therefore, agricultural land should be used towards to meeting the demand for agricultural products of the society. This requires for setting up specialized regions, building new processing plants and improvement marketing system of agricultural products.

\section{Shifting of Rural Economic Structure}

This is one of the major policies for economic development in Vietnam in the recent years. The implementation of this policy has produced positive changes in rural economy. Proportion of agricultural production is gradually declined while proportion of industry and service sectors are increased. In agriculture, land, labors, and capital have also been reallocated in orientation of promoting livestock. In crop production, non-rice crops have been given in priority for more diversified crop system. Based on these changes, efficiency of input use is increased, and household income is also improved. However, these 
changes have been seen clearly in city suburbs, coastal areas, or households having abundant capital, laborers, and management skills. The changes of economic structure are observed at very slow speed in pure agricultural areas and poor households where government policy is to invest more for agricultural extension, upgrading the infrastructure, encourage trading exchange activities among regions, and small and medium projects for rural economic development. The local government should create favorable environment for establishment of group farming, stimulate the cooperation relationship between farmers and other domestic and foreign organizations. Farm households should bring their self-reliance into making appropriate decisions for their economic development.

\section{Development of Cooperatives Under the Cooperative Law}

Agricultural cooperatives in Vietnam have experienced for around 4 decades and had a certain contribution to agricultural development and country building. However, organization structure of these cooperatives that was inflexible has caused separation from producers and capital. Long existence of these cooperatives has resulted inefficient use of resources available in rural areas, and inactivated household economy development. From this context, Politburo enacted the Resolution No. 10 (5 April 1988) on renovation of economic management mechanism in agriculture, which considered farm household as an autonomous economic unit. This was important base for innovation activities of cooperatives. This created opportunities and challenges for cooperatives, stimulated them to operate more efficiently. However, many cooperatives have broken out in confronting challenges in new environment. In the recent years, the number of cooperatives decreased from 19,201 in 1995 to 16,243 in 1998 (15.4\% decreased). At present, cooperatives can be classified into three categories according to management skills: (a) good: 2,528 cooperatives (15.5\%), (b) normal: 6,562 (40.4\%), and (c) poor: $7,153(43.3 \%)$ (Nguyen Huu Tien, 1999).

Nowadays, the existence and development of cooperatives depend mainly on farmer's perception on cooperative because farmers are both members and builders of cooperatives. Besides, government should support cooperatives in resolving stagnated problems and orienting their activities in the new environment. The development of cooperatives and managerial skills of their staffs have close relations, so upgrading the managerial skills for staffs now arises as one of the most considerable issues. According to the statistic data from 10 Northern provinces, among 1,347 chairmen of agricultural cooperatives, there were only $6.3 \%$ at the university education, $13.7 \%$ at college education, $22.4 \%$ finished primarily management skill classes, and the rest of $57.5 \%$ haven't been trained. In the Southern provinces, statistical data from 212 agricultural cooperatives surveyed showed that about 6 percent of managers were at the university education, $28.2 \%$ at college education, $35.1 \%$ at primarily managerial skill classes, and remains of $30.7 \%$ has not been trained. Also at these cooperatives, professional staff also showed a low training level with $2.5 \%$ at university, $17.1 \%$ at intermediate level, $37.7 \%$ at primarily school, and $44.7 \%$ has not been trained (Report of MARD, cited by Nguyen Huu Tien, 1999). This status reflects an urgent requirement of improving the managerial skills for the cooperative's staffs. 


\section{Investment in Rural Areas}

Despite having abundant potentials, rural development can not itself become dynamic if there are not exogenous supports. Investment, especially establishment of small and medium enterprises with their advantages of capital, managerial skills, technology and markets can receive benefits when investing into rural areas where resources are abundant and have not been exploited, yet. The investment should be focused on some following areas:

- Investment for producing non-agricultural products (such as clothes, leathers, traditional handicrafts, etc.) for domestic consumption and for exports based on the advantages of surplus labor forces in rural areas.

- Investment of new technologies for processing agricultural and aquacultural products in order to improve quality, increase competitiveness and economic efficiency of that products.

- Looking for markets and signing in product contracts with farmers, especially for special and exportable products. To make the contracts into effects, the investors should provide some capital and materials at first, then, purchase products of farmers after harvest.

The small and medium enterprises are favorable types for efficient use of resources in rural areas nowadays. In order to call investment in rural areas, the supports of Government as well as favorable environment creativeness from local authorities for helping investors are necessary.

\section{Establishment a Stable Market and Reform Agricultural Price Policy}

Results of recent surveys in rural areas have showed that the markets of agricultural products are vital prerequisite for agricultural and rural development. In the past, with the self-sufficient production, trade had taken place at the local markets in small scopes, and markets were not an important, yet. However, under the market oriented economy, expansion of markets arises as an urgent requirement for production. In rural areas of Vietnam, expansion of markets is facing with following problems of (1) the low purchasing power of domestic markets, and (2) weak competitiveness of commodity due to low quality, but high production cost, and simple type, (3) seasonal and regional characteristics of agricultural products, and (4) poor post harvest technology. Thus, increasing product quality to the standard of the regional countries and the world and improving the competitiveness of the agricultural products are the requirement and very necessary. In addition, seeking opportunities for market expansion both in domestic and international should be paid more attention.

At present, low agricultural product prices and negative relative prices between agricultural and industrial commodities have caused farmers facing with many disadvantages. With very limited crop areas, farmers now face the prospect of stagnant incomes. How to resolve and overcome this situation is much being considered.

\section{Participation of Poor Rural People in the Market Oriented Rural Economy}

This means that to empower poor rural people to participate effectively in the new market-oriented rural economy through increasing their access to improved inputs such as fertilizers, seeds, credits, services (agricultural extension, training, market information, 
etc.), as well as post-harvest processing technologies and markets. In this context access to improved basic physical and social infrastructure should be expanded. The implementation of five land use rights should also be accelerated. The participation of poor people should be facilitated in any activities of rural society.

\section{CONCLUSION}

One of the most encouraging aspects of Viet Nam's development process in recent years has been the promotion of major economic reforms by the Government through a market-oriented economic development strategy. Early attempts to reform the centrally planned and collectivized economy began in the early 1980s, with the introduction of market-based incentive structures, such as individual contracting in the agricultural sector. But the key turning point at the policy level took place at the Sixth Party Congress in December 1986, with the adoption of a "renovation" policy, which embraced both the will to reform the domestic economy and the determination to 'open the door' towards the international community and Southeast Asia in particular. The implementation of substantive market-oriented reforms was accelerated during 1989-94, including the liberalization of most prices; the decollectivization of agriculture and the return to family-based farming; the devaluation and unification of exchange rates; significant nationalization of the public sector including state-owned enterprises (SOEs); and the maintenance of high interest rates. Viet Nam also began to actively promote foreign trade, direct foreign investment and development co-operation.

However, Vietnam is facing now with challenges especially the last two years due to Asian financial crisis and declining of economic growth.. For further development of the country it is necessary to pay more attention to rural economy. Besides the constitutional reform, seven key issues mentioned above are main solutions for authors to accelerate the development process of rural economy in Vietnam.

\section{REFERENCE}

Chu Huu Quy, 1998. Impacts of Industrialization and Modernization and Establishment Production Relations Towards Socialism. Hanoi.

General Statistical Office (GSO), 1998. Statistical Yearbook 1997. Statistical Publishing House, Hanoi. GSO, 2000. Vietnam Living Standard Survey 1997-1998. Statistical Publishing House. Hanoi.

Izumida, Yoichi, 2000. Agricultural Structure Problems in Vietnam. The University of Tokyo, Japan. Scientific Paper No. 00-F-002, July 2000.

Ministry of Labors, Invalid and Social Affair (MOLISA), Vietnam, 2000. New Criteria for Poverty in the Period of 2000-2005. Hanoi, November 2000.

Nguyen Huu Tien, 1999. Major Issues Related to Agricultural Cooperatives in Vietnam. The Paper presented at the Joint Workshop on Agricultural Cooperatives and Policy Issues in Japan and Vietnam between the Faculty of Economics and Rural Development, Hanoi Agricultural University (HAU) and HAU-JICA ERCB Project held at HAU, 11-13 August 1999.

Nguyen Van Bich, 1997. Cooperative Transformation and Development. The State Political Publishing House, Hanoi.

Nguyen Xuan Nguyen, 1998. Some Issue of Production Relations of Agricultural and Rural Development Based on Experiences of Asian Countries. Hanoi.

Pham Ngoc Anh, 1999. Agricultural Cooperative Transformation under Cooperative Law: Actual Situation and Future Direction. Hanoi.

Pham Van Dinh, 1999. Agricultural Cooperatives Issues in Vietnam. The Paper presented in the Joint 
Workshop on Agricultural Cooperatives and Policy Issues in Japan and Vietnam between the Faculty of Economics and Rural Development, Hanoi Agricultural University (HAU) and HAU-JICA ERCB Project held at HAU, 11-13 August 1999.

Pham Van Dinh, 1999. Some Overview of Agriculture of Taiwan in the Process of Modernization, Hanoi. Resolution No. 10 of Politburo of the Central Committee of the Communist Party. Hanoi, 1988.

The Actual Situation of Labors-Employment in Vietnam 1997. Statistical Publishing House,. Hanoi, 1998.

Trainop, 1991. Summary of Lectures on Cooperatives. Moscow.

UN, December 1998a. Expanding Choices for the Rural Poor, Hanoi.

UNDP Vietnam. Annual Report 1999, Hanoi.

UNDP, April 1998a. Vietnam Agriculture: A Review of Trends and Issues. Prepared by Lincoln International Ltd. as part of "Strengthening Capacity for the Renewal of Rural Development in Vietnam (phase 1)", (VIE/96/008).

FAO, April 1999. Rural Development Chapter. The draft by FAO Vietnam. A part of Common Country Assessment (CCA) for Vietnam.

Pham Van Hung, 1999. Inventory and Assessment of Innovative Financial Organizations Directed Towards the Poorer Population in Vietnam. A part of Multi-Country Project on Rural Financial Policies and Food Security for the Poor. Institute of Agricultural Economics and Social Sciences in the Tropics, University of Hohenheim and IFPRI. September, 1999.

Pham Van Hung and Nguyen Minh Hien, 2000. The Vegetable Marketing System. The Paper presented in the Joint Workshop on Rural Economy Development in the Red River Delta of Vietnam between the Faculty of Economics and Rural Development, Hanoi Agricultural University (HAU) and HAU-JICA ERCB Project held at HAU, 26-28 June 2000. 